\title{
A Cross-Cultural Analysis of the Influence of Psychological Needs and Cultural Individualism on Problematic Internet Use
}

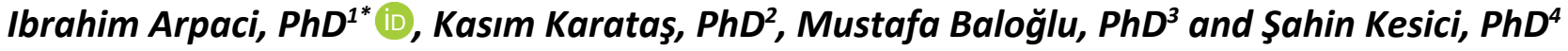 \\ ${ }^{1}$ Department of Software Engineering, Bandirma Onyedi Eylul University, Balıkesir, Turkey \\ ${ }^{2}$ Department of Educational Sciences, Karamanoglu Mehmetbey University, Karaman, Turkey \\ ${ }^{3}$ School of Education, Hacettepe University, Ankara, Turkey
}

${ }^{4}$ Department of Educational Sciences, Ahmet Keleşoglu Faculty of Education, Necmettin Erbakan University, Konya, Turkey

*Corresponding author: Ibrahim Arpaci, PhD, Department of Software Engineering, Bandirma Onyedi Eylul University, Balıkesir, Turkey

\begin{abstract}
This study presents a cross-cultural analysis of the influence of psychological needs and cultural individualism on problematic Internet use. The Individualism-Collectivism Scale, New Needs Assessment Questionnaire, and Internet Addiction Scale were used to collect data from American and Turkish college students. A structural equation modeling based multi-group analysis was employed to test the research model and hypothesized relationships. The results showed that there is a negative and significant relationship between psychological needs of achievement and problematic Internet use in both groups. Whereas there was a positively significant relationship between vertical individualism and problematic Internet use in both groups, that relationship was stronger in the U.S. sample. The findings indicated that cultural background has a significant influence on problematic Internet use and the risk of problematic Internet use is higher in the individualist societies.
\end{abstract}

\section{Keywords}

Individualism, Problematic internet use, Psychological needs

\section{Introduction}

According to the International Telecommunication Union [1], $79.6 \%$ of individuals in Europe; $71.3 \%$ of the Commonwealth of Independent States; 69.6\% of America; $54.7 \%$ of Arab States; $47 \%$ of Asia/Pacific countries; and $24.4 \%$ of African nations use the Internet. Such an extensive use of the Internet has considerable effects on contemporary people's habits and behaviors. More specifically, problematic Internet use is associated with certain personal, social, or vocational problems. Therefore, it can be said that a large proportion of people throughout the world are susceptible to problematic Internet use, which usually presents itself as inability to avoid overusing the Internet, excessive time spent online, nervousness and aggression when deprived of the Internet, and the deterioration of one's work, social, and family life [2]. Although not yet considered as an impulse control disorder under the umbrella of psychiatric disorders in DSM-5 (APA, 2014) or International Classification of Diseases (ICD-11), problematic Internet use threatens both physiological and psychological health [3] and such problems are becoming more common [4]. This study focused on a cross-cultural investigation of the relationships between psychological needs, cultural individualism and problematic Internet use. A comparison of the US and Turkey is conducted to determine whether there are differences in the proposed relationships between two cultures.

\section{Literature Review}

\section{Cultural theory}

Today, it is seen that problematic Internet use is a global problem that exceeds cultures, races, ages and genders [2]. In fact, many studies on problematic

Citation: Arpaci I, Karataş K, Baloğlu M, Kesici S (2021) A Cross-Cultural Analysis of the Influence of Psychological Needs and Cultural Individualism on Problematic Internet Use. Int Arch Addict Res Med 6:033. doi.org/10.23937/2474-3631/1510033

Accepted: November 06, 2021: Published: November 08, 2021

Copyright: (c) 2021 Arpaci I, et al. This is an open-access article distributed under the terms of the Creative Commons Attribution License, which permits unrestricted use, distribution, and reproduction in any medium, provided the original author and source are credited. 
Internet use are being carried out in several countries around the world [5] and it still continues [6,7]. There are numerous social and psychological reasons that cause people to become addicted to the Internet and there are many problems that cause them to become addicted. For example, in various research studies, it is claimed that low self-esteem, identity problem, depression, anxiety, loneliness and aggression are important causes of problematic Internet use $[8,9]$. However, attention deficit, social phobia, hyperactivity disorder, drug use, psychotic disorders, and mood disorders are seen in Internet addicts [10-13].

Problematic Internet use is a condition that develops depending on the personality traits of individuals and has a negative effect on individuals psychosocially. Indeed, personality traits (e.g., neuroticism as a risk factor and conscientiousness as a protective factor) have a significant direct and indirect effect on problematic Internet use [14]. In addition, it has been found that there is a connection between traits of loyalty, selfesteem [15,16], self-construal [12] neuroticism [17] coping style [18] agreeableness, emotional stability, personality, specifically conscientiousness $[19,20]$ and problematic Internet use. However, one of the factors that play an important role in the development of problematic Internet use in individuals is the cultural traits of the country in which they live in [21]. As culture is effective in acquiring and developing personality traits [22], and it brings the individual a unique identity within the general rules. In addition, each culture represents a different way of life, and the diversity of the cultures differentiates individuals [23-26]. In other words, the unique nature, boundaries and diversity of each culture form an individual's frame of reference and prepare the basis for individual differences. In order to make sense of the characteristics and behavioral aims of the people who develop within the culture, it is necessary to understand the main causes of the emotional and intellectual behavior in that society [27]. Therefore, various cultural theories have been put forward concerning how cultural factors shape individuals' behavior. Of these theories, individualism and collectivism provide explanations as to what the underlying factors in the behavior of individuals are. It is stated that cognitive, emotional and motivational behavior differ according to the individualist and collectivist state of the culture in which people are born [28]. Similarly, Triandis [29] states that in collectivist cultures, people are extremely dependent on the norms of the group they are in and tend to achieve the group's goals before individual goals. Moreover, it is stated that people living in individualistic cultures tend to exhibit autonomous and independent behavior and are motivated to transcend the norms of the group and achieve their individual goals.

In individualism and collectivism, there are two basic dimensions: horizontal and vertical. Horizontal individualism means self-confidence, trying to be unique, and being 'individual', by behaving differently from the group. Vertical individualism, on the other hand, refers to competitiveness; focus on success and acting according to hedonist tendencies. On the other hand, while horizontal collectivism is conceptualized as interdependence among members of a group, resembling others, and working for the goodness of the group, vertical collectivism means providing and maintaining family integrity, sacrificing personal goals for the group's goals, and being able to sacrifice by following the group norms [30,31].

Today, it is stated that people living in the United States and Western Europe have more individual cultural perspectives; in China, Turkey, Japan and Korea, individuals have collectivist perspectives [32]. Therefore, it is usual that the characteristic traits and psychological needs of individuals living in these countries vary according to the cultural orientation of the societies in which they live, whether they are individualist or collectivist. For example, in collectivist societies, individuals tend to co-operate, offer social support, support equality and exhibit integrity. In individualist cultures, individuals prioritize values such as success, anomie, alienation, social recognition and individual gains [33]. In this context, when making judgments about the psychological needs of individuals, cultural references are important criteria. Ozyesil [34] argued that undergraduate students in the US had higher awareness and autonomy, competence and relationship need, which are all sub-dimensions of psychological need, than Turkish University students. This situation is attributed to the importance of individuality in US culture.

\section{Psychological needs}

Regardless of culture, individuals have universal psychological needs. Glasser identifies five basic needs built into our genetic structure: Belonging, survival, power, fun, and freedom [35]. However, Ryan and Deci [36] state that psychological needs are competence, relationship and autonomy. Heckert, et al. [37] state that social interaction and desire to be accepted by others shape psychological needs. It is known that individuals provide individual well-being, and that quality of life increases if they satisfy their psychological needs, otherwise, psychological needs cannot be met, and it may cause various problems. One of these situations is problematic Internet use. Individuals may prefer to meet certain psychological needs that they cannot meet in daily life via the Internet. For example, they meet their relationship and autonomy needs using social media; online games to complete tasks and achieve competency [38]. Shen, Liu, and Wang [39] states that as long as individuals meet their psychological needs from daily life, they will use the Internet more positively, otherwise 
they try to meet their psychological needs using the Internet in a problematic way and, in such a case, they increase problematic Internet usage. Individuals who are inadequate at establishing and maintaining social relationships, that is, exhibiting high levels of shyness and social anxiety, may choose to meet these needs in a virtual environment [40]. Similarly, individuals who are seeking social support, or who are anxious and lonely, but who do not meet these needs in their immediate environment may develop problematic Internet use $[41,42]$. In this context, although the Internet is seen as a tool for the elimination of psychological needs, it is a situation that can lead to different psychological problems by turning into addiction.

In the light of a literature review, there appears to be a relationship between psychological needs and problematic Internet use. Moreover, problematic Internet use is a universal problem which transcends across cultures. At this point, it is important to examine the relationship between problematic Internet use and psychological needs based on cultural structure, and to shed a culture-oriented light on the problem by making cross-cultural comparison. In addition, the role of cultural structure in the relationship between psychological needs and problematic Internet use is a matter of curiosity. The aim of this study was to investigate the influence of psychological needs and cultural individualism on problematic Internet use. In addition, it is anticipated that the type of psychological needs specific to cultures will be revealed, and that it will stimulate ideas regarding the potential of problematic Internet use depending on the cultural structure. The research questions to be answered in this study are as follows:

RQ1. Is there a relationship between horizontal and vertical individualism and problematic Internet use?

RQ2. Is there a relationship between psychological needs and problematic Internet use?

RQ3. Is there a significant difference between the US and Turkey in the proposed relationship?

\section{Methodology}

\section{Sample and procedure}

Out of the 359 valid responses, there were 109 participants (96 women, 13 men) from the United States (U.S.) and there were 250 participants (163 women, 87 men) from Turkey. The respondents were aged between 21 and 26-years-old (Mean = 24.89, SD $=7.86)$. Majority of the respondents are students in Kean University (18.4\%), Texas A\&M University (12\%), Tokat Gaziosmanpasa University (TOGU) (38.9\%), and Hacettepe University (27.6) majoring in different departments such as applied psychology, clinical counselling, and school counselling. Concerning the educational level, $70.2 \%$ of the respondents were bachelor's degree students, followed by master's degree students with $29.3 \%$, and PhD degree students with $5 \%$. $48.6 \%$ of the students reported that their daily usage of Internet is more than 5 hours. The research protocol was approved by Human Subjects Committee of the TOGU. After signing a consent form, the participants completed the Internet-based surveying (Qualtrics).

\section{Instrument}

\section{The Individualism-Collectivism (INDCOL) Scale}

Singelis, et al. [43] developed the INDCOL scale and Wasti and Erdil [44] adapted it into Turkish. There are18 five point Likert items measuring horizontal and vertical individualism. Cronbach's alpha values were found as 0.82 and 0.81 for the vertical and horizontal individualism, respectively.

\section{The New Needs Assessment Questionnaire (NNAQ)}

Heckert, et al. [37] developed a five-point 20 item Likert-type scale, which includes four subscales "affiliation, autonomy, achievement, and dominance." The Turkish NNAQ adapted by Kesici [45] was used in the present study. Cronbach's alpha values ranged from 0.70 to 0.79 .

\section{The Internet Addiction Scale (IAS)}

Chen, et al. [46] developed a four point 26-item Likert scale, which includes five subscales: "withdrawal, compulsive use, tolerance, interpersonal and health problems, and time management". The Turkish IAS adapted by Kesici and Sahin [47] was used in the present study. Cronbach's alpha value of the total scale was 0.96 .

\section{Results}

\section{Validity and reliability}

Cronbach's alpha values were used to be test measurements reliability. The Cronbach's alpha values ranged from 0.70 to 0.96 , the alpha values exceeded the threshold value of 0.70 [48]. Thus, the results indicated that reliability of each scale was satisfactory. Further, correlation analysis results suggested that there was a positive correlation between vertical individualism and problematic Internet use. Further, the results, shown in Table 1, suggested that there was a negative correlation between achievement and problematic Internet use.

Confirmatory Factor Analysis (CFA) was conducted by using SPSS AMOS (ver.23) to evaluate factor structure of the structural model and measurement model. Based on the reference value(s) [49], it can be suggested model fit indices indicated a satisfactory model fit. The results shown in Table 2 provided evidence for the construct validity.

\section{Structural model}

A multi-group analysis was performed to test 
Table 1: Reliability and correlations

\begin{tabular}{|c|c|c|c|c|c|c|c|c|}
\hline Scale & $\alpha$ & 1 & 2 & 3 & 4 & 5 & 6 & 7 \\
\hline 1. IAS & 0.95 & 1.00 & & & & & & \\
\hline 2. Vertical Ind. & 0.82 & $0.221^{*}$ & 1.00 & & & & & \\
\hline 3. Horizontal Ind. & 0.81 & 0.046 & 0.093 & 1.00 & & & & \\
\hline 4. Achievement & 0.75 & $-0.241^{*}$ & 0.111 & 0.158 & 1.00 & & & \\
\hline 5. Affiliation & 0.77 & 0.066 & -0.015 & $-0.298^{* *}$ & 0.176 & 1.00 & & \\
\hline 6. Autonomy & 0.70 & 0.021 & 0.143 & $0.410^{* *}$ & $0.282^{* *}$ & -0.112 & 1.00 & \\
\hline 7. Dominance & 0.79 & 0.160 & $0.394^{* *}$ & 0.181 & $0.318^{* *}$ & $0.199^{*}$ & $0.261^{* *}$ & 1.00 \\
\hline
\end{tabular}

$" p<0.05, " p<0.01$

Table 2: CFA results.

\begin{tabular}{|c|c|c|c|c|c|}
\hline \multirow[t]{2}{*}{ Fit Indices } & \multicolumn{3}{|c|}{ Measurements } & \multirow[t]{2}{*}{ Structural Model } & \multirow{2}{*}{$\begin{array}{l}\text { Reference } \\
\text { Value(s) }\end{array}$} \\
\hline & Individualism & NNAQ & IAS & & \\
\hline$X^{2}(\mathrm{DF})$ & $255.586(86)$ & $93.344(30)$ & $697.387(254)$ & $1162.029(461)$ & \\
\hline$p$ value & $<0.001$ & $<0.001$ & $<0.001$ & $<0.001$ & \\
\hline$X^{2} / d f$ & 2.97 & 3.11 & 2.75 & 2.52 & $<3$ \\
\hline GFI & 0.95 & 0.97 & 0.92 & 0.90 & $\geq 0.90$ \\
\hline AGFI & 0.93 & 0.95 & 0.90 & 0.88 & $\geq 0.80$ \\
\hline $\mathrm{NFI}$ & 0.93 & 0.91 & 0.94 & 0.87 & $\geq 0.90$ \\
\hline TLI & 0.93 & 0.90 & 0.95 & 0.90 & $\geq 0.90$ \\
\hline CFI & 0.95 & 0.94 & 0.96 & 0.91 & $\geq 0.90$ \\
\hline IFI & 0.95 & 0.94 & 0.96 & 0.92 & $\geq 0.90$ \\
\hline RMSEA & 0.05 & 0.06 & 0.05 & 0.05 & $\leq 0.08$ \\
\hline SRMR & 0.05 & 0.05 & 0.04 & 0.08 & $\leq 0.08$ \\
\hline
\end{tabular}

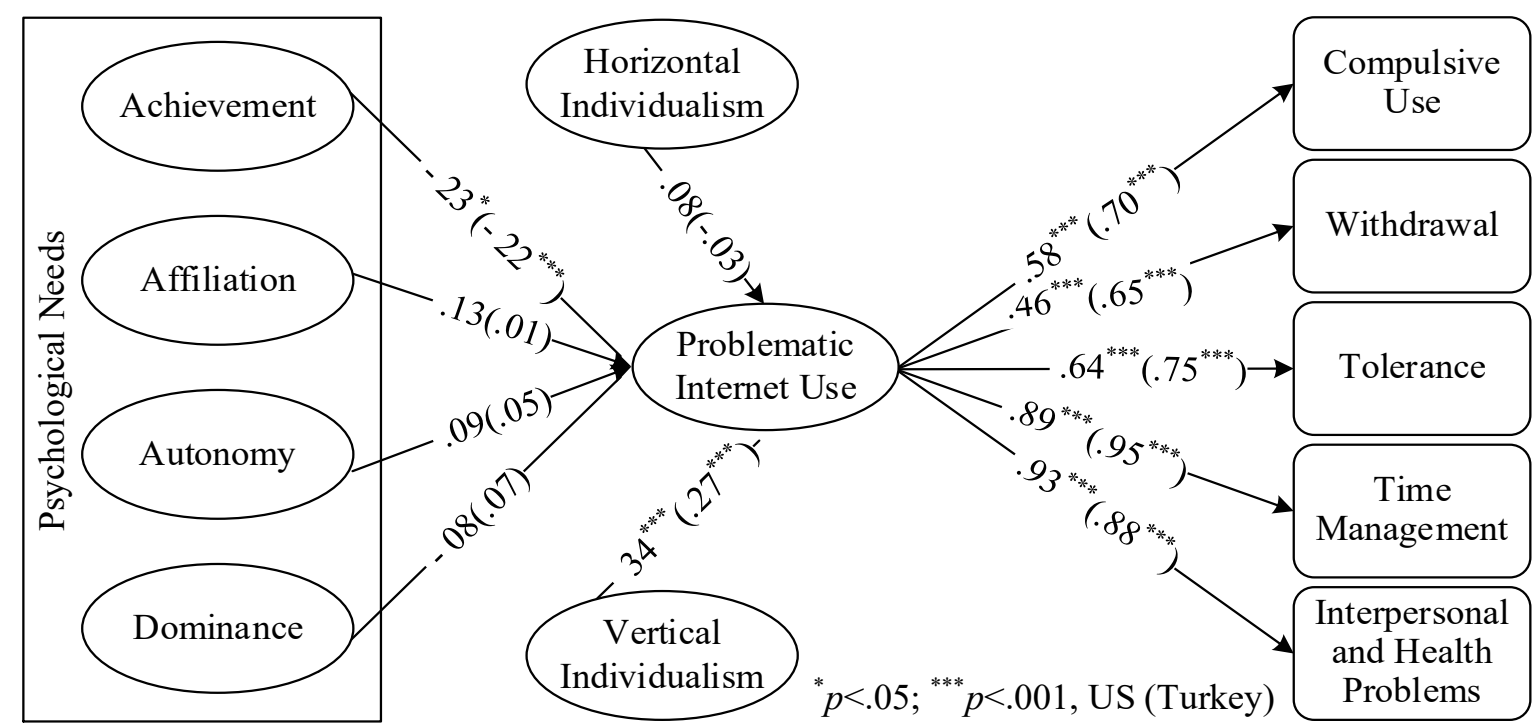

Figure 1: Structural model.

differences in the structural model between the US and Turkey. In the structural model, there are five observed variables with total scores measuring the PIU, which is predicted by the subscales of psychological needs and individualism-collectivism. In Figure 1, latent variables were represented in ellipse. The structural model was tested over a bootstrapping procedure of 5000 resamples by evaluating the standardized regression weights ( 6$), t$-values, and $p$ values. The results for the US indicated that achievement negatively predicts problematic Internet use $(B=-0.234, t=-2.257, p<$ $0.05)$. Results also indicated that vertical individualism positively predicts problematic Internet use $(B=$ $0.340, t=3.316, p<0.001)$. Similarly, the in results for Turkey showed that achievement negatively predicts problematic Internet use $(B=-0.218, t=-4.858, p$ 
Table 3: Multi-group analysis results.

\begin{tabular}{|l|l|l|l|l|l|}
\hline Path & Std. $\beta$ & $\beta$ & S.E. & C.R. & $p$ \\
\hline Ach $\rightarrow$ PIU & $-0.234(-0.218)$ & $-0.915(-1.26)$ & $0.405(0.261)$ & $-2.25(-4.85)$ & $0.024^{*}\left(0.001^{* *}\right)$ \\
\hline Aff $\rightarrow$ PIU & $0.126(0.012)$ & $0.501(0.004)$ & $0.412(0.089)$ & $1.21(0.047)$ & $0.225(0.962)$ \\
\hline Aut $\rightarrow$ PIU & $0.086(0.046)$ & $0.445(0.351)$ & $0.572(0.382)$ & $0.778(0.919)$ & $0.437(0.358)$ \\
\hline Dom $\rightarrow$ PIU & $-0.075(0.071)$ & $-0.905(0.197)$ & $1.09(0.119)$ & $-0.827(1.65)$ & $0.408(0.097)$ \\
\hline HI $\rightarrow$ PIU & $0.084(-0.025)$ & $0.056(-0.010)$ & $0.061(0.016)$ & $0.915(-0.654)$ & $0.360(0.513)$ \\
\hline VI $\rightarrow$ PIU & $0.340(0.273)$ & $0.199(0.107)$ & $0.060(0.015)$ & $3.31(6.93)$ & $0.001^{* *}\left(0.001^{* *}\right)$ \\
\hline
\end{tabular}

${ }^{*} p<0.05 ;{ }^{* *} p<0.001$, Problematic Internet Use (PIU), Vertical Individualism (VI), Horizontal Individualism (HI), Achievement (Ach), Affiliation (Aff), Autonomy (Aut), Dominance (Dom), U.S. (Turkey).

$<0.001)$. Whereas vertical individualism positively predicts problematic Internet use $(B=.273, t=6.93, p<$ 0.001) (Figure 1).

Nested model comparisons suggested that the overall model was not significantly different between the countries $\left(\chi^{2}=1,818, \mathrm{DF}=4, p>0.05\right)$. Further, examination of the standardized estimates shown in Table 3 suggested that the relationship between vertical individualism and problematic Internet use was stronger in the US than in Turkey.

\section{Discussion and Conclusion}

\section{Key findings}

In this study, relationships between psychological needs, vertical and horizontal individualism and problematic Internet use is examined. A comparison of the US and Turkey is conducted to determine whether there are differences in the proposed relationships between two cultures. According to the findings, problematic Internet usage decreases as the need for success increases from psychological needs, and problematic Internet usage increases as the need for success decreases. Studies from different cultures in the literature [50-53] are consistent with the findings of this study. Khuon states that individuals with a high need for success motivate themselves from internal and external sources and set high standards of success. Ozyesil [34] states that individuals will endeavor to develop their existing potential to meet the need for success. In this sense, individuals in need of success focus their interest and motivation on success. Individuals with this awareness avoid trends and behavior that may become dependent on the Internet because individuals who need success generally believe that achieving high success will make them more valuable [36]. Therefore, in the case of being dependent on the Internet, individuals will not be able to provide sources of success for achieving and sustaining success and will not be able to perform adequately in social interaction. Research has shown that the risk of problematic Internet use increases the tendency of individuals to social phobia, depression and anxiety, and negatively affects their social skills, as well as their physical and psychological development [54,55]. The Internet can be seen by many people as a means of meeting psychological needs with its different functions. However, it does not meet the psychological needs, but rather deepens the psychological needs. In fact, there was a negative relationship between problematic Internet use and individually well-being, which is an important indicator of meeting psychological needs $[56,57]$. Cheng and Li [5] found a negative correlation between problematic Internet use and individual wellbeing and quality of life according to the results of a meta-analysis conducted in thirty-one countries. Cardak [58] states that the psychological well-being of Turkish university students with high levels of problematic Internet use is low and, therefore, psychological wellbeing is negatively affected by problematic Internet use. In another study, Burger (2004) stated that the meaning of success may vary from culture to culture and that in individualist cultures, such as the US, success is generally considered as personal success. In collective cultures like Turkey, it implies that more co-operation and group success is defined as success. This study shows that, even if the meanings attributed to success in different cultures change, the relationship between the need for success and problematic Internet use is negative.

One of the findings of this research, the relationship between the US and vertical individualism is that problematic Internet use is stronger than in Turkey. Pew Research Center [59] reported that Internet usage has become an integral part of our lives with nine out of ten adults in the U.S. use the Internet. Whereas, with cases of individualism and collectivism, it is important to understand how societies' attitudes towards social and psychological events relate to culture $[60,61]$. It is known that levels of Internet dependence may vary according to country of residence and culture $[15,62]$. It has been stated that countries with a culture of individualism have a higher rate of Internet use [63]. Problematic Internet use is predicted to be higher in individualist societies [64]. Stavropoulos, Alexandraki and Motti-Stefanidi [65] reports that there is a relationship between individualism and problematic Internet use and that the situation triggers hedonism. In fact, Joshanloo and Jarden [66] find that there is a positive relationship between individualistic societies and hedonism by collecting data from nineteen different countries. Individuals in individualist societies prioritize their own happiness and 
attach importance to individual success. Similarly, they rely on themselves and do not want to be dependent on others, and they try to solve their own problems and achieve their own goals [67]. In the same way, Kagitcibasi [68] states that individuals in individualist cultures have a discrete/isolated self-structure and that their social interaction orientations are low. On the other hand, there is a positive relationship between problematic Internet use and social isolation $[4,69]$. In this context, individuals in individualist societies are influenced by competitive structure, and they are likely to see the Internet as an important tool to quickly develop their own competencies, meet their psychological needs, and achieve their individual goals quickly. It is thought that such individuals will tend to use the Internet more often. Based on this possibility, it can be expected that individualistic societies have much more problematic Internet use potential.

\section{Implications for research and practice}

The findings indicated that there was a relationship between problematic Internet use and certain psychological needs (i.e., achievement). Based on the findings, it can be argued that cultural background has a significant influence on problematic Internet use and the risk of problematic Internet use is higher in the individualist societies. In this context, societies that exhibit individualism traits should conduct information and awareness studies to prevent individuals from using the Internet in a problematic manner. This is because problematic Internet use is a problem that puts, not only the individuals, but also the psychological and physiological health of the whole society at risk. In this regard, all institutions, especially educational institutions, should show sensitivity to this issue and enlighten the public on the benefits of Internet use and the damage caused by problematic Internet use. In addition, alternative ways should be developed to meet psychological needs in a healthy way.

This study is conducted to compare the countries of Turkey and the USA in the intended field. Future researchers could examine the relationship between psychological needs and problematic Internet use by comparing countries with different cultural traits. They could also test the mediation of different psychological variables. Another limitation is the imbalanced samples; Turkish participants double the US. The gender ratio is also large, which is particularly biased in the US sample. Findings of this research should be tested using qualitative research techniques (interview, observation, and so on) on the variables of culture, problematic Internet use and psychological needs.

\section{Compliance with Ethical Standards}

\section{Ethical approval}

All procedures performed in studies involving human participants were in accordance with the ethical standards of the institutional and/or national research committee and with the 1964 Helsinki declaration and its later amendments or comparable ethical standards.

\section{Informed consent}

Informed consent was obtained from all individual participants included in the study.

\section{Conflict of interest}

Authors declare none.

\section{Data availability}

Data will be available upon request.

\section{References}

1. International Telecommunication Union (2018) Individuals using the Internet per 100 inhabitants.

2. Young K (2015) The evolution of Internet addiction disorder. In: C. Montag, M. Reuter, Internet addiction, Studies in neuroscience, psychology, and behavioral economics. New York, NY: Springer, 3-17.

3. Choi J, Cho H, Lee S, Kim J, Park EC (2018) Effect of the online game shutdown policy on Internet use, Internet addiction, and sleeping hours in Korean adolescents. J Adolesc Health 62: 548-555.

4. Tateno M, Teo AR, Ukai W, Kanazawa J, Katsuki R, et al. (2019) Internet addiction, smartphone addiction, and Hikikomori trait in Japanese young adult: Social isolation and social network. Front Psychiatry 10: 455.

5. Cheng C, Li AYL (2014) Internet addiction prevalence and quality of (real) life: A meta analysis of 31 nations across seven world regions. Cyberpsychol Behav Soc Netw 17: 755-760.

6. Arpaci I (2019) Culture and nomophobia: The role of vertical versus horizontal collectivism in predicting nomophobia. Information Development 35: 96-106.

7. Arpaci I, Baloğlu M, Kesici Ş (2018) The relationship among individual differences in individualism-collectivism, extraversion, and self-presentation. Personality and Individual Differences 121: 89-92.

8. Gill DS (2019) A study of loneliness in relation to Internet addiction among adolescents. International Journal of Research in Social Sciences 9: 362-370.

9. Koo HJ, Kwon JH (2014) Risk and protective factors of Internet addiction: A meta-analysis of empirical studies in Korea. Yonsei Med J 55: 1691-1711.

10. Arisoy Ö (2009) Internet addiction and its treatment. Current Approaches in Psychiatry 1: 55-67.

11. Caplan SE (2006) Relations among loneliness, social anxiety, and problematic Internet use. Cyberpsychol Behav 10: $234-242$

12. Hawi N, Samaha M (2019) Identifying commonalities and differences in personality characteristics of Internet and social media addiction profiles: Traits, self-esteem, and self construal. Behaviour \& Information Technology 38: 110-119.

13. Tas I (2019) Association between depression, anxiety, stress, social support, resilience and Internet addiction: A structural equation modelling. Malaysian Online Journal of Educational Technology 7: 1-10. 
14. Koronczai B, Kökönyei G, Griffiths MD, Demetrovics $Z$ (2019) The relationship between personality traits, psychopathological symptoms, and problematic Internet use: A complex mediation model. J Med Internet Res 21: e11837.

15. Błachnio A, Przepiorka A, Gorbaniuk O, Benvenuti M, Ciobanu AM, et al. (2019) Cultural correlates of Internet addiction. Cyberpsychol Behav Soc Netw 22: 258-263.

16. Gentile A, Servidio R, Caci B, Boca S (2018) Social stigma and self-esteem as mediators of the relationship between Body Mass Index and Internet addiction disorder. An exploratory study. Current Psychology 40: 1262-1270.

17. Kayis AR, Satici SA, Yilmaz MF, Şimşek D, Ceyhan E, et al. (2016) Big five-personality trait and Internet addiction: A meta-analytic review. Computers in Human Behavior 63 35-40.

18. Chwaszcz J, Lelonek-Kuleta B, Wiechetek M, Niewiadomska I, Palacz-Chrisidis A (2018) Personality traits, strategies for coping with stress and the level of Internet addiction-A study of polish secondary-school students. International Journal of Environmental Research and Public Health 15: 987

19. Sulaiman A, Shin KY, Rofaie N (2019) Personality traits and Internet addiction among selected financial institution employees. Int J Environ Res Public Health 35: 260-271.

20. Przepiorka A, Blachnio A, Cudo A (2019) The role of depression, personality, and future time perspective in Internet addiction in adolescents and emerging adults. Psychiatry Research 272: 340-348.

21. Hu E, Stavropoulos V, Anderson A, Clarke M, Beard C, et al. (2019) Assessing Online Flow Across Cultures: A Two-Fold Measurement Invariance Study. Frontiers in Psychology 10: 1-12.

22. Haviland WA (2002) Cultural anthropology. Wadsworth Publishing Company.

23. Burton L, Delvecchio E, Germani A, Mazzeschi C (2019) Individualism/collectivism and personality in Italian and American Groups. Current Psychology 40: 29-34.

24. Hu Q, Bernardo AB, Lam SW, Cheang PK (2018) Individualism-collectivism orientations and coping styles of cyberbullying victims in Chinese culture. Current Psychology 37: 65-72.

25. Tychmanowicz A, Filipiak S, Sprynska Z (2019) Extravert individualists or introvert collectivists? Personality traits and individualism and collectivism in students in Poland and Ukraine. Current Psychology 5434.

26. Mellor S (2019) Confidence at Work and IndividualismCollectivism: An Empirical Demonstration of the Distinctiveness of American Union Employees. Current Psychology 38: 542-555.

27. Benedict R (1934) Patterns of culture (Vol. 8). Houghton Mifflin Company.

28. Markus HR, Kitayama S (1991) Culture and the self: Implications for cognition, emotion, and motivation. Psychological Review 98: 224-253.

29. Triandis HC (2001) Individualism-collectivism and personality. Journal of Personality 69: 907-924.

30. Chiou JS (2001) Horizontal and vertical individualism and collectivism among college students in the United States, Taiwan, and Argentina. The Journal of Social Psychology 141: $667-678$
31. Park H, Rehg MT, Lee D (2005) The influence of Confucian ethics and collectivism on whistle blowing intentions: A study of South Korean public employees. Journal of Business Ethics 58: 387-403.

32. Neuliep JW (2016) Intercultural communication: A contextual approach. Sage Publications.

33. Tastan S, Torun A (2015) The examination of the relations of cultural values, embeddedness, trust and environmental uncertainty with organizational social capital structure: A research among small and medium size enterprises. International Refereed Social Sciences 49: 412-439.

34. Ozyesil Z (2012) Mindfulness and psychological needs: A cross-cultural comparison. Elementary Online 11: 151-160.

35. Frey LM, Wilhite K (2005) Our five basic needs: Application for understanding the function of behavior. Intervention in School and Clinic 40: 156-160.

36. Ryan RM, Deci EL (2017) Self-determination theory: Basic psychological needs in motivation, development, and wellness. Guilford Publications.

37. Heckert TM, Cuneio G, Hannah AP, Adams PJ, Droste $\mathrm{HE}$, et al. (2000) Creation of a new needs assessment questionnaire. Journal of Social Behavior and Personality 15: $121-136$

38. Wong TY, Yuen KS, Li WO (2015) A basic need theory approach to problematic Internet use and the mediating effect of psychological distress. Frontiers in Psychology 5: 1562.

39. Shen CX, Liu RD, Wang D (2013) Why are children attracted to the Internet? The role of need satisfaction perceived online and perceived in daily real life. Computers in Human Behavior 29: 185-192.

40. Hong W, Liu RD, Oei TP, Zhen R, Jiang S, et al. (2019) The mediating and moderating roles of social anxiety and relatedness need satisfaction on the relationship between shyness and problematic mobile phone use among adolescents. Computers in Human Behavior 93: 301-308.

41. Saikia AM, Das J, Barman P, Bharali MD (2019) Internet addiction and its relationships with depression, anxiety, and stress in urban adolescents of Kamrup District, Assam. Journal of Family \& Community Medicine 26: 108-112.

42. Prievara DK, Piko BF, Luszczynska A (2019) Problematic Internet use, social needs, and social support among youth. International Journal of Mental Health and Addiction 17: 1008-1019.

43. Singelis TM, Triandis HC, Bhawuk DPS, Gelfand MJ (1995) Horizontal and vertical dimensions of individualism and collectivism: A theoretical and measurement refinement. Cross-cultural Research: 29: 240-275.

44. Wasti A, Erdil ES (2007) Measurement of individualism and collectivism: Validation of the self-construal scale and INDCOL in Turkish. Management Research Journal 7: 3966.

45. Kesici S (2008) The validity and reliability study of the Turkish version of the new psychological needs assessment scale. Selcuk University Social Sciences Journal 20: 493500

46. Chen SH, Weng LJ, Su YJ, Wu HM, Yang PF (2003) Development of a Chinese Internet addiction scale and its psychometric study. Chinese Journal of Psychology 45: 279-294.

47. Kesici S, Sahin I (2010) Turkish adaptation study of Internet addiction scale. Cyberpsychol Behav Soc Netw 13: 185-189. 
48. Nunnally JC, Bernstein IH (1994) Psychometric theory. McGraw-Hill, New York.

49. Hair J, Hollingsworth CL, Randolph AB, Chong AYL (2017) An updated and expanded assessment of PLS-SEM in information systems research. Industrial Management \& Data Systems 117: 442-458.

50. Arbabisarjou A, Gorgich EAC, Barfroshan S, Ghoreishinia G (2016) The association of Internet addiction with academic achievement, emotional intelligence and strategies to prevention of them from students' perspectives. International Journal of Humanities and Cultural Studies (IJHCS) 3: 1656-1666.

51. Eldeleklioglu J, Vural M (2013) Predictive effects of academic achievement, Internet use duration, loneliness and shyness on Internet addiction. Hacettepe University Journal of Education 28: 141-152.

52. Li Y, Yao C, Zeng S, Wang X, Lu T, et al. (2019) How social networking site addiction drives university students' academic achievement: The mediating role of learning engagement. Journal of Pacific Rim Psychology 13: e19.

53. Xu X, Wang J, Peng H, Wu R (2019) Prediction of academic performance associated with Internet usage behaviors using machine learning algorithms. Computers in Human Behavior 98: 166-173.

54. Obeid S, Saade S, Haddad C, Sacre H, Khansa W, et al (2019) Internet addiction among Lebanese adolescents: The role of self-esteem, anger, depression, anxiety, social anxiety and fear, impulsivity, and aggression-a cross-sectional study. The Journal of Nervous and Mental Disease 207: 838-846.

55. Wei HT, Chen MH, Huang PC, Bai YM (2012) The association between online gaming, social phobia, and depression: An Internet survey. BMC Psychiatry 12: 92.

56. Seabra L, Loureiro M, Pereira H, Monteiro S, Marina Afonso $\mathrm{R}$, et al. (2017) Relationship between Internet addiction and self-esteem: cross-cultural study in Portugal and Brazil. Interacting with Computers 29: 767-778.

57. Sharma A, Sharma R (2018) Internet addiction and psychological well-being among college students: A crosssectional study from Central India. Journal of Family Medicine and Primary Care 7: 147-151.
58. Cardak M (2013) Psychological well-being and Internet addiction among university students. Turkish Online Journal of Educational Technology-TOJET 12: 134-141.

59. Pew Research Center (2018) Internet/broadband fact sheet.

60. Triandis HC, Gelfand MJ (1998) Converging measurement of horizontal and vertical individualism and collectivism. Journal of Personality and Social Psychology 74: 118-128.

61. Dong K, Liu Y (2010) Cross-cultural management in China. Cross Cultural Management: An International Journal 17: 223-243.

62. Lopez-Fernandez O (2015) Cross-cultural research in Internet addiction: A systematic review. International Archives of Addiction Research and Medicine 1: 011.

63. Erumban AA, De Jong SB (2006) Cross-country differences in ICT adoption: A consequence of culture? Journal of World Business 41: 302-314.

64. Arpaci I, Kesici Ş, Baloğlu M (2018) Individualism and Internet addiction: The mediating role of psychological needs. Internet Research 28: 293-314.

65. Stavropoulos V, Alexandraki K, Motti-Stefanidi F (2013) Recognizing Internet addiction: Prevalence and relationship to academic achievement in adolescents enrolled in urban and rural Greek high schools. Journal of Adolescence 36: 565-576.

66. Joshanloo M, Jarden A (2016) Individualism as the moderator of the relationship between hedonism and happiness: A study in 19 nations. Personality and Individual Differences 94: 149-152.

67. Ma V, Schoeneman TJ (1997) Individualism versus collectivism: A comparison of Kenyan and American selfconcepts. Basic and Applied Social Psychology 19: 261273.

68. Kagitcibasi C (2006) Yeni insan ve insanlar [New human and people]. Istanbul: Evrim Publishing.

69. Muhammad NM, Schneider M, Hill A, Yau DM (2019) How the use of iPad and smartphones creates social isolation. In Society for Information Technology \& Teacher Education International Conference, 1060-1065. Association for the Advancement of Computing in Education (AACE). 